\title{
A Forensic Economics Approach to Reparations
}

\author{
Joel N. Morse \\ University of Baltimore
}

House of Representatives, $113^{\text {th }}$ Congress Bill 40 , introduced on January 6, 2015, by Representative John Conyers, Democrat of Michigan, suggests that reparations should be paid to descendants of people who were enslaved in the United States and its predecessors between 1619 and 1865. The bill is conceptual and political, but short on the details of reparation amounts and eligibility.

The Official Title, as introduced to the House of Representatives reads "To address the fundamental injustice, cruelty, brutality, and inhumanity of slavery in the United States and the 13 American colonies between 1619 and 1865 and to establish a commission to study and consider a national apology and proposal for reparations for the institution of slavery, its subsequent de jure and de facto racial and economic discrimination against African-Americans, and the impact of these forces on living AfricanAmericans, to make recommendations to the Congress on appropriate remedies, and for other purposes. ${ }^{, 2}$

The spirit of the bill is captured by Section 3, Paragraph B.1.D "the treatment of African slaves in the colonies and the United States, including the deprivation of their freedom, exploitation of their labor, and destruction of their culture, language, religion, and families."

I propose a very preliminary conceptual model that may be useful in addressing the reparations issue. The model relies on a standard forensic economics framework utilized in U.S. courts.

\section{INTRODUCTION}

In a typical personal injury litigation situation, a wrong (known as a tort) is brought to a trier-of-fact for analysis and possible recompense or "making the victim whole."

Typically, the first step is to estimate income "but for" the wrongdoing, and subtract from that an estimate of post-injury income. This is a year-by-year calculation, carried forward through worklife expectancy. The latter is not simply the age at which Social Security benefits are accessible. Rather, it nets out time out of the labor force, for all sorts of reasons such as illness, caring for loved ones, educational updates and voluntary or involuntary work interruptions. Next, the difference, or loss, in each year, is discounted to present value. This discounting process reflects the earning power ${ }^{3}$ of a lump sum award, thus avoiding over-compensation of the plaintiff.

In the reparations context, a likely initial data acquisition goal might involve assessing prevailing wages in the historical period covered by H.R. 40 (1619-1865). To this end, an early step would be to review economic history journals, to ascertain if such an estimate is possible. 
Similarly, one would need to make an estimate of the average price of subsistence room and board. Since, despite the horror of the conditions in many cases, slavery did provide room and board, that amount would be subtracted from the prevailing wage. That differential would be the first quantum of a forensic economics approach damage calculation. Typically, in current forensic practice, increments for fringe benefits are addressed. This is hard to estimate in the H.R. 40 review period (1619-1865), and will not be addressed here, since they were likely rather small, if they existed at all.

However, unlike today's job environment, room and board for self and family was apparently provided, albeit at a subsistence level. I will implicitly incorporate the idea of benefits, food and housing by mitigating lost income by a very high personal maintenance offset.

Before moving to the overwhelming issue of accumulated interest, also known as "opportunity cost" in economics, we comment on the dramatic issue of enslavement itself. This travesty is reminiscent of an economic loss concept that is currently admissible in only a few U.S. jurisdictions. ${ }^{4}$ The term used is "hedonic damages," a referral to the loss of the enjoyment of life. The economic literature with respect to hedonic valuation speaks to non-trivial sums, based on studies of how much people will pay to avoid risks. However, applicability in the present discussion is fraught with computational and conceptual difficulties, and in fact may be secondary to the more accessible issue of accumulated interest.

In modern courtroom settings, accumulated interest is referred to as pre-judgment interest. A delay in access to funds denies the plaintiff the opportunity to deploy the earned money in a profitable way. In typical litigation, the number of years is limited, and interest is not a major element of damages. However, given the multi-century outlook of H.R. 40, accumulated, or pre-judgment interest might well comprise the largest component of reparations, if Congress were to deem it "admissible." Of course, the identification and verification of lineal descendants adds both issues of "standing," as parties are called in litigation, and administrative complexity. Nevertheless, pro-actively, it is worth examining the interest rate issue.

If reparations can possibly be thought of as a lost profits metaphor from a litigation context, it may contribute to our understanding of the context of House Bill 40 to append a political or cultural viewpoint.

Incomes and net worth of African-American households and individuals lag those of other sub-sets of the American population. It is beyond the scope of this note to delve into causation. However, there is an emerging voice that links at least some of this monetary gap to the legacy of slavery and subsequent inequities in housing policy and lending practice.

Naturally, in a time of expanding federal debt levels, a massive budget line item for reparations will face intense scrutiny. However, there are some precedents for related initiatives. We have seen reparations for Japanese-Americans interned after Pearl Harbor. Native Americans have large landholdings in quasi-independent enclaves in many states. Israel negotiated reparations directly with Germany, on behalf of Holocaust victims.

The Atlantic [2014] publication of Ta-Nehisi Coates, "The Case For Reparations," eloquently lays out the rationale as well as the history. An organization called The Trans-Atlantic Slave Trade Database ${ }^{6}$ maintains a vast set of resources and documentation. Further work is available from Professor William Darity's projects at Duke University. ${ }^{7}$ Nevertheless, in Dailycaller [2016], President Obama notes the political infeasibility of this initiative.

For these reasons, I outline a conceptual framework for estimating the interest rate for assessing prejudgment interest over hundreds of years, based on U.S. legal precedent for individual torts, that might promote continued examination of the reparations issue

The bulk of the damage estimate in this context would be pre-judgment interest, because of the vast time horizon between the original alleged tort and the present. In normal or current litigation and civil courts, pre-judgment interest is not a matter for an expert opinion to specify. Rather, it tends to be statutory. However, there are no laws, rulings or precedents that cover the extraordinarily long prejudgment timeframe in the context of reparations.

In traditional litigation, the purpose of pre-judgment interest is twofold. First, its purpose is to compensate the claimant for lack of timely access to the funds quantified in the damage award. Second, it is to ensure that the defendant, maintaining access to the funds, does not profit from delays in the 
litigation process. To some extent, the purpose here is also to deter continued or future malfeasance of the sort identified in the extant litigation.

The context of reparations differs. First, consider the United States government, as a defendant in the sense that it would be the ultimate payer of reparations. Unlike most traditional litigation, where a person or an organization can be defined, tracked and identified, the defendant in this context is rather amorphous.

For example, over the century-and-a-half, approximately, since enslavement, the United States government has gone through countless changes of elected officials, organizational format and political party. Thus, it is not clear that past tortious behavior carries to any identifiable party today in a clear way.

Further, in terms of assessing blame, although the government, until the Civil War, provided the legal environment that permitted slavery, the actual enslavement was uniformly conducted by private U.S. citizens, not by government bodies.

Thus, Conyers bill's assertion, that the U.S. government pay reparations shifts blame from a multiplicity of potential private tortfeasors to, essentially, the U.S. taxpayer of today.

However, United States taxpayers, as the ultimate funders of federal expenditures, now include presumably, descendants of both enslaved individuals, as well as descendents of those who owned and employed slaves. In other words, there is considerable overlap between the payer of reparations and the receiver of reparations!

Due to the ancient and difficult to document lineage of both those enslaved and those allegedly responsible for the enslavement, the usual background and rationale for prejudgment interest is not clearly in place.

Therefore, I propose that the rate of pre-judgment interest should be lower than seen in contemporary litigation. Indeed, since preventing a continuation of enslavement, is moot since the Civil War and President Lincoln's Emancipation Proclamation eradicated slavery, one of the rationales for assessing prejudgment interest is absent.

So, what remains is to estimate a sense of any economic loss during then bill's stated time horizon, and to compensate the appropriate parties for the immensely long delay in receiving damages or compensation. House Bill 40 identifies as potential recipients, essentially, present-day citizens, many of whom are likely descendants of the enslaved in the "tort window." Therein, it is also suggested that organizations oriented toward advancement in African-American life in are also to be included in reparations payments.

Defining, identifying and verifying legitimate recipients of reparations, obviously an issue of great import, is beyond the scope of this paper. Since whatever procedures, identifications and protocols emerge will likely recognize both the opportunity cost of capital that arises from the unprecedented delay, as well as some estimate of the original loss, the total calculation issue is vast in complexity, and vast in importance.

This paper will concentrate only on the rate of pre-judgment interest. I defer to future research the question of the quantification of the original loss. One approach would be to assess the prevailing wage structure for the panoply of work associated with enslavement in the appropriate range of years. This complex research falls in the realm of economic historians and their data sources.

However, below I suggest that a reasonable substitute approach may be available. Using current income statistics, and oft-cited personal consumption tables, I am able to provide illustrative examples that show the potential magnitude of reparations.

\section{PRE-JUDGMENT INTEREST}

At almost any nonnegative rate, the accumulated interest component of reparations will be immense, due to the passage of well over a century.

From Expectancy Data, 2016, I extract the average wage for all persons, with a $9^{\text {th }}$ through $12^{\text {th }}$-grade education. That figure is $\$ 24,202.00$. Next, using the Patton-Nelson tables of personal consumption, I assume that the approximate level of net savings is $5 \%$. Thus, my basic building block for "damage 
calculations" is $\$ 1,210.10$. This data source, derived from the American Community Survey, cited below) states income in 2014 dollars. I convert this, using the rate of change of the CPI-U index, to 2018 dollars by multiplying the $\$ 1,210$ by 1.07 , resulting in a constant dollar equivalent of $\$ 1,294.80$.

Further, conservatively, recognizing the shorter life spans, unhealthy living conditions and uncertain work life expectancies likely prevalent in the damage years, I assume 20 years of work. This yields $\$ 25,896.14$.

Continuing to leap forward with what may be deemed speculation, I assume, for illustrative purposes, that the original enslaved population was about 100,000 people. ${ }^{8}$ In turn, this results in a lump sum of $\$ 2,589,614,000$.

Finally, using a real rate of return (Duff and Phelps, 2017) of $2.60 \%$, and assuming the mid-point of House Bill 40's range of 1619-1865 (1742), I estimate the 2018 value of $\$ 2,589,614,000$ as $\$ 3,089,630,960,384$. Yes, three trillion dollars! ${ }^{9}$

I note that if I utilize a net savings fraction of $2.5 \%$, the overall loss estimate drops by about $50 \%$. Further research is suggested on the topics of support, consumption and wage rates.

In conclusion, we see the immense effect of pre-judgment interest on the calculus of reparations as suggested in House Bill 40. Since House Bill 40 lacks specific suggestions for quantifying reparations, the efforts in this paper may be of use to policy makers.

\section{ENDNOTES}

1. https://www.congress.gov/bill/113th-congress/house-bill/40 This was re-introduced by Rep. Jackson Lee in the 115th (2017-2018) Congress https://www.congress.gov/bill/115th-congress/house-bill/40

2. https://www.congress.gov/bill/115th-congress/house-bill/40/all-info

3. Presumably an award earns interest, dividends and capital gains when invested by a successful plaintiff.

4. I am not espousing the use of hedonic damages in extant civil litigation. I mention the term for illustrative purposes only.

5. See Moore and Viscusi [1988].

6. http://www.slavevoyages.org/

7. Interview, $2017 \mathrm{https}: / /$ thenextsystem.org/for-reparations

8. Harvard professor Henry Louis Gate, Jr. estimates that the actual number of imported slaves was about 450,000. Of course, deeper calculations will require some sense of the size of the ongoing enslaved population https://www.theroot.com/how-many-slaves-landed-in-the-us-1790873989.

9. A spreadsheet that contains my calculations is available on request. 


\section{REFERENCES}

American Community Survey (n.d.). Retrieved from http://www.census.gov/acs/www/

Coates, T-N. (2014, June). The Case For Reparations. The Atlantic. Retrieved from https://www.theatlantic.com/magazine/archive/2014/06/the-case-for-reparations/361631/

Darity, Jr., W. (2017, March 10). For Reparations: A Conversation with William A. Darity, Jr. Retrieved from https://thenextsystem.org/for-reparations

Duff \& Phelps (2017). SBBI (Stocks, Bonds, Bills and Inflation Yearbook, Exhibit 2-3.

Full-Time Earnings in the United States (2016). Reported from The American Community Survey, U.S. Census Bureau. Retrieved from http://www.census.gov/acs/www/ Shawnee Mission, KS, 2016.

This is the source for the data on income from the American Community Survey, whose ultimate source is [http://www.census.gov/acs/www/].

Gates, H.L. (2014, January 6). How Many Slaves Landed in the US? Retrieved from https://www.theatlantic.com/magazine/archive/2014/06/the-case-for-reparations/361631/

Gates, H.L. (n.d.). Slave Voyages. Retrieved from http://www.slavevoyages.org/

Moore, M.J., \& Viscusi, W. (199, July 26). Kip, The Quantity-Adjusted Value of Life. Economic Enquiry, 26, 369-388.

Randal, A. (2016, December 22). Obama: I can't Pursue Reparations because it's Politically Infeasible. Retrieved from http://dailycaller.com/2016/12/22/obama-i-cant-pursue-reparations-because-itspolitically-infeasible/ 